\title{
Efek Moderasi Resiliensi terhadap Hubungan antara Perfeksionisme dengan Kecemasan Mengerjakan Skripsi
}

\author{
Moderation Effect of Resilience towards Relationship between \\ Perfectionism and Anxiety in Working on Mini Thesis
}

\author{
Delila Nurbani Diah ${ }^{1}$, Fitriani Yustikasari Lubis ${ }^{2}$, Witriani Witriani ${ }^{3}$ \\ Fakultas Psikologi, Universitas Padjadjaran
}

Submitted 12 April $2020 \quad$ Accepted 22 Juli $2020 \quad$ Published 27 Oktober 2020

\begin{abstract}
In the process of writing mini thesis, the demands and standards set from the outside can trigger students to become perfectionists in setting up their standard, followed by excessive evaluation in achieving the perfectionistic standard. Consequently, it causes anxiety during minithesis completion. Students facing stressful events need resilience which could help their academic performance. This study aimed to find how resilience moderates on the relationship between perfectionism and anxiety on writing mini-thesis. Data were collected from 109 undergraduate students of faculty of psychology 2016 who were completing their mini thesis. Perfectionism was measured using Hewitt \& Flett's Multidimensional Perfectionism Scale, anxiety was measured using State Anxiety Inventory, and resilience was measured using Inventory for College Students Resilience. The collected data was analyzed hierarchically by moderation regression using an absolute difference test method. The research found that self-oriented perfectionism $(p=0.051 ; p<0.10)$ and socially prescribed perfectionism $(p=0.000 ; p<0.10)$ have effects on anxiety during mini-thesis completion. Meanwhile, resilience does not significantly moderate the relationship between perfectionism and anxiety during mini-thesis completion.
\end{abstract}

Keywords: anxiety on writing thesis; perfectionism; resilience; student

\begin{abstract}
Abstrak. Dalam proses menulis skripsi, adanya tuntutan dan standar yang ditetapkan dari luar dapat memicu mahasiswa menjadi perfeksionis dalam menetapkan standar pengerjaan skripsinya, serta diikuti dengan evaluasi yang berlebihan pada pencapaiannya. Hal ini menyebabkan dapat menimbulkan kecemasan dalam mengerjakan skripsi. Untuk menghadapi keadaan ini, mahasiswa membutuhkan resiliensi yang diharapkan dapat membantunya bertahan agar tetap menghasilkan performa yang baik. Penelitian ini bertujuan untuk melihat efek moderasi resiliensi terhadap hubungan antara perfeksionisme dengan kecemasan mengerjakan skripsi. Penelitian dilakukan dengan menyebarkan kuesioner kepada 109 mahasiswa fakultas psikologi angkatan 2016 yang sedang mengambil mata kuliah skripsi. Perfeksionisme diukur dengan menggunakan Hewitt $\mathcal{E}$ Flett's Multidimensional Perfectionism Scale, kecemasan diukur menggunakan State Anxiety Inventory, serta resiliensi diukur dengan menggunakan Inventory for College Students Resilience. Pengolahan data dilakukan dengan analisis regresi moderasi secara hierarki melalui metode uji selisih mutlak. Hasil yang diperoleh menunjukkan bahwa self-oriented perfectionism $(p=0,051 ; p<0,10)$ dan socially prescribed perfectionism ( $p=0,000 ; p<0,10)$ secara langsung memiliki pengaruh positif terhadap kecemasan mengerjakan skripsi. Sementara, resiliensi tidak terbukti dapat memoderasi hubungan antara perfeksionisme dengan kecemasan mengerjakan skripsi.
\end{abstract}

Kata kunci: kecemasan mengerjakan skripsi; mahasiswa; perfeksionisme; resiliensi

Korespondensi mengenai artikel ini dapat dilakukan melalui delilanurbanid@gmail.com 
Skripsi merupakan suatu karya ilmiah yang ditujukan sebagai tugas akhir dan syarat kelulusan yang menuntut penguasaan materi-materi dalam mata kuliah yang telah diikuti oleh mahasiswa selama masa kuliahnya. Selain itu, skripsi juga menuntut mahasiswa untuk melakukan penelitian secara benar sesuai dengan kaidah yang berlaku (Siswanto \& Sampurno, 2013). Idealnya, skripsi dapat diselesaikan oleh mahasiswa selama satu semester atau enam bulan, pada semester ke-7 maupun ke-8. Skripsi memiliki bobot 6 SKS yang setara dengan 24 - 30 jam perminggu atau $600-$ 750 jam persemester. Pada kenyataannya, setiap mahasiswa membutuhkan waktu yang berbeda-beda untuk menyelesaikannya. Hal ini terjadi karena adanya faktor, baik internal maupun eksternal mahasiswa dalam menyelesaikan skripsi yang berbeda-beda. Faktor internal misalnya, adanya pengaruh dari pola pikir, kepribadian, keyakinan, atau bagaimana mereka meregulasi diri (Aslinawati \& Mintarti, 2018 Barseli \& Ifdil, 2018). Selain itu, terdapat faktor eksternal yang lebih sulit dikendalikan oleh mahasiswa itu sendiri, seperti, tugas akademik yang menunjang penyelesaian skripsi itu sendiri, tekanan untuk berprestasi tinggi, serta lingkungan sosialnya (Gunawati, Hartati, \& Listiara, 2006).

Dalam proses pengerjaan skripsi, mahasiswa dituntut untuk bekerja secara aktif dan mandiri namun harus tetap sesuai dengan standar dan kaedah penelitian yang berlaku. Misalnya, topik penelitian berdasarkan fenomena dan permasalahan yang dapat dijelaskan melalui suatu teori. Mencari topik penelitian yang sesuai dengan minat mahasiswa dan standar penelitian merupakan hal yang tidak mudah dilakukan (Aslinawati \& Mintarti, 2018) sehingga tidak jarang mahasiswa harus mengganti topik atau judul penelitian yang diusulkan (Wiyatmo, Mundilarto, Suharyanto, \& Widodo, 2010). Tidak hanya itu, adanya tekanan dari keluarga untuk lulus tepat waktu (3,5 - 4 tahun) juga seringkali dialami oleh mahasiswa (Wiyatmo et al., 2010).

Di sisi lain, lingkungan yang kompetitif juga dapat menyebabkan kecemasan mahasiswa dalam mengerjakan skripsinya. Hal ini dapat menjadikan mahasiswa cenderung membandingkan dirinya dengan mahasiswa lainnya yang telah memiliki proses yang lebih maju, misalnya telah melakukan seminar usulan penelitian atau telah mencapai proses pengambilan data. Mahasiswa akan semakin merasa tertekan untuk mencapai hasil yang setara atau bahkan lebih baik dan unggul dalam proses pengerjaan skripsinya.

Dalam kondisi yang sangat menekan, individu cenderung merasakan adanya standar kesempurnaan (perfeksionisme) dari lingkungannya dan mereka kurang mampu meregulasi dirinya untuk mengelola pikirannya dari hal-hal negatif (Flett, Hewitt, Blankstein, \& O'Brien, 1991). Dalam konteks penyusunan skripsi, berbagai tekanan dapat menyebabkan mahasiswa merasakan stress sehingga mendorong sikap perfeksionis. Mahasiswa akan menetapkan standarstandar yang tinggi serta berupaya keras untuk mencapainya tanpa mempertimbangkan kemampuan yang dimiliki. Jika standar yang ditetapkannya semakin tidak realistis dan tidak tercapai, 
mereka akan cenderung mengalami dampak negatif, misalnya perasaan gagal yang berlebihan dan menjadi ragu akan kemampuannya di berbagai kegiatan mendatang.

Persepsi adanya standar kesempurnaan ini dapat muncul akibat adanya tekanan dari lingkungan. Mahasiswa menganggap bahwa orangorang di sekitarnya berekspektasi terhadap dirinya untuk mencapai standar skripsi tertentu. Keyakinan adanya tuntutan dari lingkungan menekan mereka sehingga menjadi perfeksionis dalam mengerjakan skripsi, terlepas ada atau tidaknya trait perfeksionis yang dimiliki. Menurut Hewitt dan Flett (1991), hal ini disebut sebagai socially prescribed perfectionism. Tipe perfeksionis ini bersifat maladaptif karena menyebabkan individu terlalu memikirkan standar yang ditetapkan oleh orang lain sehingga menjadi ragu untuk bertindak. Mereka akan cenderung berfokus pada bagaimana dirinya dapat memuaskan ekspektasi orang lain terhadapnya. Keraguan tidak tercapainya standar ini akan menghasilkan kecemasan akan kemampuannya.

Perfeksionisme juga dapat meningkatkan evaluasi diri yang kritis pada mahasiswa. Artinya, mahasiswa akan cenderung mengkritik segala hal terkait dirinya. Kemudian, ia akan membandingkan hasilnya dengan standar tinggi (sempurna) yang dipasangnya sehingga ia tidak pernah merasa cukup atas dirinya. Apabila mengalami suatu kegagalan, evaluasi diri yang berlebihan ini akan menyebabkan mahasiswa cenderung menyalahkan dirinya sendiri dan meyakini segala kemampuan yang dimilikinya merupakan suatu hal yang melekat dan tidak dapat diubah. Dengan begitu, mahasiswa akan cenderung tidak meyakini kemampuannya dan kehilangan motivasi untuk mengatasi atau menghadapi situasi sehingga cenderung menghindarinya (Besser, Flett, \& Hewitt, 2004). Kecenderungan yang terus-menerus ini akan berkontribusi dalam pengembangan dan pertahanan terjadinya kecemasan. Selain itu, perfeksionisme juga dapat menyebabkan rendahnya regulasi diri yang akan menghasilkan strategi coping yang buruk pula (Eddington, 2014) sehingga berdampak pada pencapaian tujuan awal yang tidak sesuai target, yang dalam hal ini ialah penyelesaian skripsi.

Ketidakmampuan dalam menyesuaikan standar yang ditetapkan dengan keadaan diri yang sebenarnya dapat menyebabkan mahasiswa merasa tidak berdaya (Hong, Chiu, Dweck, Lin, \& Wan, 1999). Mahasiswa juga cenderung merasa kurang adanya dukungan sosial dari lingkungan sekitarnya. Mereka pun juga merasa tidak memiliki significant others yang dapat dijadikan tempat berbagi cerita serta dimintakan bantuan darinya. Keadaan-keadaan yang maladaptif ini akan berkontribusi dalam pengembangan dan pertahanan terjadinya kecemasan (Hewitt \& Flett, 2002) sehingga berdampak pada pencapaian tujuan awal yang tidak sesuai target, yang dalam hal ini ialah penyelesaian skripsi.

Dalam menghadapi keadaan seperti ini, dibutuhkan kemampuan untuk bertahan atau tetap stabil agar dapat beradaptasi dengan tekanan yang ada, sehingga terhindar dari kemungkinan hasil yang buruk. Kemampuan ini disebut 
dengan resiliensi. Menurut Masten (2001), resiliensi merupakan suatu proses dalam beradaptasi atau berkembang yang membuahkan hasil yang baik meskipun mengalami kondisi yang mengancam. Beberapa peneliti pun sepakat bahwa resiliensi dapat menghambat dampak negatif yang mungkin terjadi walaupun seseorang terpapar dengan situasi stres. Sejalan pula dengan penelitian yang dilakukan oleh Sari dan Suhariadi (2019) bahwa mahasiswa yang resilien memiliki kemampuan untuk mempersiapkan dirinya dalam menghadapi kesulitan sehingga menjadi langkah antisipasi bagi mereka meminimalkan dampak dari peristiwa stres serta upaya untuk bangkit dan tetap mempertahankan performanya dengan optimal.

Fenomena yang diangkat dalam penelitian ini ialah pada mahasiswa Fakultas Psikologi Universitas Padjajaran (Unpad) angkatan 2016 yang sedang mengambil mata kuliah skripsi. Hal ini didasari dengan adanya kebijakan baru dari instansi mengenai diberlakukannya pekan khusus pelaksanaan seminar dan sidang yang ditentukan oleh pihak instansi yang bertujuan agar mahasiswa terpacu untuk lulus tepat waktu. Kebijakan ini disampaikan dalam sosialisasi resmi yang melibatkan seluruh mahasiswa Fakultas Psikologi Unpad angkatan 2016 di awal semester mereka mengambil mata kuliah skripsi. Studi awal dilakukan dengan menyebarkan kuesioner berbasis online dengan menggunakan Google Form kepada seluruh mahasiswa Fakultas Psikologi Unpad angkatan 2016. Berdasarkan data yang terkumpul, mahasiswa ini tertekan dengan adanya standar-standar yang harus dicapai, seperti pemahaman yang mendalam mengenai topik skripsi yang dibahas, penggunaan sumber literatur yang terpercaya, serta minimalisasi terjadinya kesalahan penulisan. Selain itu, ditetapkannya kebijakan baru tersebut dirasakan mahasiswa sebagai tuntutan untuk lulus tepat waktu. Berbagai tekanan untuk menyelesaikan skripsi sesuai standar-standar yang berlaku ini menyebabkan mahasiswa merasakan stres, takut, dan cemas. Oleh karena itu, peneliti ingin melihat apakah terdapat efek moderasi resiliensi terhadap hubungan antara perfeksionisme dengan kecemasan mengerjakan skripsi pada Mahasiswa Fakultas Psikologi Unpad angkatan 2016.

\section{Metode}

Penelitian ini menggunakan metode penelitian korelasional. Populasi dalam penelitian ini adalah mahasiswa Fakultas Psikologi Universitas Padjadjaran angkatan 2016 yang sedang mengambil mata kuliah skripsi. Berdasarkan data yang diperoleh dari Sub Bagian Akademik Fakultas Psikologi Unpad, tercatat 122 mahasiswa yang sesuai dengan kriteria penelitian. Teknik sampling yang digunakan dalam penelitian ini ialah total population sampling, yang membutuhkan seluruh anggota populasi sebagai sampel penelitian (Etikan, Musa, \& Alkassim, 2016). Sampel penelitian yang diperoleh bergantung pada kesediaan calon responden untuk berpartisipasi dalam penelitian dan mengumpulkan kuesioner penelitian yang telah diisi pada saat hari pengambilan data. Sampel yang diperoleh sebanyak 109 mahasiswa berusia 19-22 tahun, yang terdiri dari 100 orang 
perempuan dan 9 orang laki-laki. Pengambilan data penelitian dilakukan melalui kuesioner berbasis paper and pencil yang dibagikan kepada seluruh target sampel penelitian.

Dalam penelitian ini, perfeksionisme (masing-masing dimensi self-oriented perfectionism, other-oriented perfectionism, dan socially prescribed perfectionism) berperan sebagai variabel bebas, kecemasan mengerjakan skripsi sebagai variabel terikat, dan resiliensi sebagai variabel moderator. Perfeksionisme diukur melalui alat ukur Hewitt \& Flett's Multidimensional Perfectionism Scale (HMPS; Hewitt \& Flett, 1991) yang terdiri dari tiga dimensi dengan 42 aitem total dengan skala Likert 1-7 (Sangat Tidak Setuju hingga Sangat Setuju). Alat ukur ini memiliki reliabilitas sebesar 0,933 pada dimensi self-oriented perfectionism, 0,754 pada dimensi otheroriented perfectionism, dan 0,766 pada dimensi socially prescribed perfectionism. Selain itu, alat ukur ini juga telah dilakukan validasi melalui Scale-Content Validity Index dengan memeroleh persetujuan dari para expert sehingga alat ukur ini dikatakan valid (S-CVI > 0,83). Kecemasan mengerjakan skripsi diukur melalui State Anxiety Inventory (SAI; Spielberger, 1966): Alat ukur ini telah melalui uji reliabilitas dengan hasil sebesar 0,905 dan uji validitas melalui Confirmatory Factor Analysis melalui program SPSS Amos Graphics version 24 dengan hasil bahwa model fit berdasarkan kriteria Root Mean Square Error of Approximation (RMSEA <0,06), Incremental Fit Index (IFI > 0,095), dan Comparative Fit Index (CFI > 0,95). Resiliensi partisipan diukur melalui Inventory of College Students Resilience (ICSR; Huang \& Lin, 2013).
Instrumen ini mengukur empat dimensi dengan jumlah aitem sebanyak 24 . Reliabilitas alat ukur resiliensi ini sebesar 0,862 pada alat ukur secara keseluruhan, sebesar 0,635 pada dimensi empathy and interpersonal interaction, sebesar 0,773 pada dimensi cognitive maturity, dan sebesar 0,766 pada dimensi problem solving ability, dan sebesar 0,552 pada dimensi hope and optimism. Uji validitas juga telah dilakukan melalui S-CVI dengan menunjukkan bahwa alat ukur ini valid $(\mathrm{S}-\mathrm{CVI}>0,3)$. Ketiga alat ukur ini telah melalui proses forward and backward translation ke dalam bahasa Indonesia. Selain itu diberikan tujuh pertanyaan terbuka sebagai data penunjang, seperti “Hal apa saja yang Anda miliki, yang menurut Anda dapat membantu Anda mencapai standar yang Anda tetapkan dalam proses pengerjaan skripsi? (sebutkan sebanyak-banyaknya. misal: dukungan orang sekitar, kemampuan memanajemen waktu, dsb)"; "Hambatan apa saja yang dialami selama proses pengerjaan skripsi? (sebutkan sebanyak-banyaknya)".

Data yang didapatkan diolah dengan melakukan analisis regresi moderasi dengan metode uji selisih mutlak. Metode ini dilakukan dengan meregresikan selisih mutlak variabel bebas terstandardisasi dengan variabel yang dihipotesiskan sebagai variabel moderasi terstandarisasi (Rachmawati, Yuniarti, \& Nohe, 2015). Analisis ini dilakukan secara bertahap (hierarki), yaitu melihat pengaruh variabel independen terhadap variabel dependen (1), kemudian ditambahkan variabel independen lainnya yang akan berperan sebagai prediktor biasa (2) dan juga moderator (3). Sebelum melakukan analisis 
Tabel 1

Data Demografis Subjek Penelitian

\begin{tabular}{lcc}
\hline \multicolumn{1}{c}{ Demografis } & Frekuensi & Persentase (\%) \\
\hline Jenis Kelamin & & \\
$\quad$ Laki - Laki & 9 & 8,3 \\
Perempuan & 100 & 91,7 \\
\hline Usia & & \\
\multicolumn{1}{c}{19} & 1 & 0,9 \\
20 & 19 & 17,4 \\
21 & 75 & 68,8 \\
22 & 13 & 11,9 \\
23 & 1 & 0,9 \\
\hline
\end{tabular}

regresi, terdapat beberapa asumsi yang harus terpenuhi (Hayes, 2018) di antaranya, uji linearitas, normalitas, homoskedastisitas, dan multikolinearitas.

\section{Hasil}

Tabel 1 merupakan deskripsi demografi subjek dalam penelitian ini.

Sebelum melakukan analisis regresi, peneliti melakukan perhitungan uji normalitas, linearitas, dan korelasi sebagai syarat uji pendahuluan. Hasil yang diperoleh menunjukkan bahwa masingmasing dimensi perfeksionisme dengan kecemasan mengerjakan skripsi, dan resiliensi memiliki normalitas p-value sebesar 0,200 sehingga data pada penelitian ini berdistribusi normal. Uji linearitas masing-masing variabel dimensi perfeksionisme dengan kecemasan mengerjakan skripsi, dan resiliensi memiliki Fsig sebesar 1,00 sehingga memenuhi asumsi linearitas. Antara masing-masing dimensi perfeksionisme dengan kecemasan mengerjakan skripsi, dan resiliensi memiliki pola acak sehingga memenuhi asumsi homoskedastisitas. Hasil yang diperoleh menunjukkan bahwa pada model regresi antara masing-masing dimensi perfeksionisme dengan kecemasan mengerjakan skripsi, dan resiliensi memiliki nilai VIF berkisar antara 1,0071,032 serta nilai tolerance berkisar antara

Tabel 2.

Statistik Deskriptif dan Korelasi Dimensi Perfeksionisme Dengan Kecemasan Mengerjakan Skripsi, dan Resiliensi

\begin{tabular}{lccccccc}
\hline \multicolumn{1}{c}{ Variabel/Dimensi } & Mean & $\begin{array}{c}\text { Deviasi } \\
\text { Standar }\end{array}$ & $\mathbf{1}$ & $\mathbf{2}$ & $\mathbf{3}$ & $\mathbf{4}$ & $\mathbf{5}$ \\
\hline 1. Self-Oriented Perfectionism & 72,79 & 14,98 & 1 & & & & \\
2. Other-Oriented Perfectionism & 40,67 & 7,79 & $0,543^{*}$ & 1 & & & \\
3. Socially Prescribed & 49,17 & 8,19 & $0,390^{*}$ & $0,230^{*}$ & 1 & & \\
$\quad$ Perfectionism & 54,66 & 10.17 & $0,187^{*}$ & $-0,012$ & $0,432^{*}$ & 1 & \\
4. Kecemasan & 92.98 & 9.04 & $0,303^{*}$ & 0,089 & $-0,152$ & $-0,334^{*}$ & 1 \\
\hline 5. Resiliensi & & & & & &
\end{tabular}

${ }^{*} p$-value $<0,10$ 
Tabel 3.

Analisis Regresi Hierarki

\begin{tabular}{|c|c|c|c|}
\hline \multirow{2}{*}{ Prediktor } & \multicolumn{3}{|c|}{ Kecemasan Mengerjakan Skripsi } \\
\hline & Adjusted $R^{2}$ & $B$ & $p$ \\
\hline $\begin{array}{l}\text { (1a) } \\
\quad \text { Zself-Oriented Perfectionism }\end{array}$ & 0,026 & 1,905 & $0,051^{*}$ \\
\hline$(2 a)$ & & & \\
\hline$Z_{\text {Self-Oriented Perfectionism }}$ & 0,188 & 3,231 & $0,001^{*}$ \\
\hline ZResiliensi & & $-4,373$ & $0,000^{*}$ \\
\hline 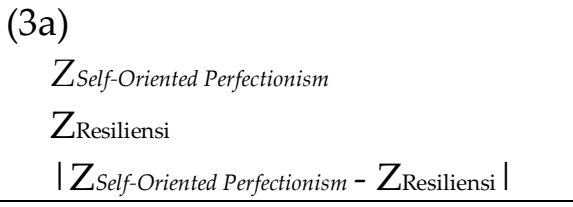 & 0,180 & $\begin{array}{l}3,217 \\
-4,360 \\
-0,257\end{array}$ & $\begin{array}{c}0,001^{*} \\
0,000^{*} \\
0,831\end{array}$ \\
\hline $\begin{array}{l}\text { (1b) } \\
\text { Zother-Oriented Perfectionism }\end{array}$ & 0,000 & $-0,126$ & 0,898 \\
\hline $\begin{array}{l}\text { (1c) } \\
\quad Z_{\text {Socially Prescribed Perfectionism }}\end{array}$ & 0,179 & 4,392 & $0,000^{*}$ \\
\hline$(2 c)$ & & & \\
\hline $\begin{array}{l}\text { Zsocially Prescribed Perfectionism } \\
\text { ZResiliensi }\end{array}$ & 0,246 & $\begin{array}{r}3,967 \\
-2,788\end{array}$ & $\begin{array}{l}0,000^{*} \\
0,002 *\end{array}$ \\
\hline (3c) & & & \\
\hline 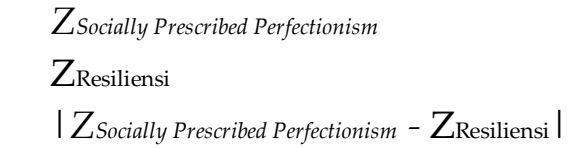 & 0,242 & $\begin{array}{c}3,921 \\
-2,784 \\
0,573\end{array}$ & $\begin{array}{l}0,001^{*} \\
0,002^{*} \\
0,504\end{array}$ \\
\hline
\end{tabular}

${ }^{*} p$-value $<0,10$

0,969-0,993 sehingga dapat dikatakan tidak terjadi multikolinear antarvariabel dalam model regresi.

Pada Tabel 2, dapat dilihat bahwa masing-masing dimensi dari perfeksionisme saling berkorelasi positif. Berdasarkan kriteria Dancey dan Reidy (2007), self-oriented perfectionism memiliki korelasi yang rendah $(r=0,187)$ dan socially prescribed perfectionism memiliki korelasi pada tingkat sedang $(r=0,432)$ dengan kecemasan mengerjakan skripsi. Selain itu, dimensi self-oriented perfectionism ini juga memiliki korelasi positif pada tingkat rendah dengan resiliensi. Sedangkan, resiliensi memiliki korelasi pada tingkat rendah $(r=-0,334)$ dengan arah negatif dengan kecemasan, artinya semakin tingginya tingkat resiliensi maka akan berhubungan dengan menurunnya tingkat kecemasan mengerjakan skripsi. Oleh karena itu, data dalam penelitian ini memenuhi syarat untuk dilakukan analisis regresi.

Untuk dapat menjawab pertanyaan penelitian maka dilakukan rangkaian regresi hirarikal untuk setiap dimensi perfeksionisme. Untuk setiap regresi, kecemasan mengerjakan skripsi diuji hubungannya dengan ketiga dimensi perfeksionisme. Kemudian dilakukan pengujian dengan memasukkan variabel moderator resiliensi. Berikut hasil dari analisis regresi pada penelitian ini: 
Berdasarkan Tabel 3, dapat dijelaskan tahapan regresi yang dilakukan. Pada model (1a), regresi yang dilakukan menunjukkan bahwa self-oriented perfectionism memiliki pengaruh yang signifikan terhadap terjadinya kecemasan mengerjakan skripsi ( $B=1,905, p=0,051$; $p<0,1)$ dengan sumbangan prediktor sebesar $2,6 \%$. Selanjutnya pada model (2a), memasukkan variabel resiliensi sebagai prediktor. Diperoleh peningkatan pengaruh sebesar $16,2 \%$ dengan peran masing-masing variabel self-oriented perfectionism dan resiliensi yang signifikan terhadap kecemasan mengerjakan skripsi. Pada model (3a), interaksi antara self-oriented perfectionism dengan resiliensi dalam bentuk nilai selisih mutlak dimasukkan sebagai variabel moderator. Hasilnya, diperoleh nilai $p$ lebih besar dari alpha $(p=0,831 ; p>0,1)$ yang berarti resiliensi tidak berperan memoderasi hubungan antara perfeksionisme dengan kecemasan mengerjakan skripsi.

Analisis regresi dilakukan untuk melihat pengaruh other-oriented perfectionism terhadap kecemasan mengerjakan skripsi (model 1b). Hasil menunjukkan nilai koefisien determinasi $R^{2}$ sebesar 0,000 dan nilai signifikansi $p$ lebih besar daripada alpha $(p=0,898 ; p>0,01)$. Artinya, otheroriented perfectionism tidak berpengaruh signifikan terhadap kecemasan mengerjakan skripsi. Dengan begitu, analisis lanjutan untuk melihat efek moderasi resiliensi tidak dilakukan.

Model (1c) Socially prescribed perfectionism memiliki pengaruh yang signifikan terhadap kecemasan mengerjakan skripsi dengan kontribusi nya sebesar 17,9\% ( $B=4,392, p=0,000 ; p<0,1)$.
Pada model (2c), regresi dilakukan dengan memasukkan resiliensi sebagai variabel prediktor. Hasil menunjukkan terjadinya peningkatan pengaruh sebesar 6,7\% dengan peran masing-masing, yaitu socially prescribed perfectionism memiliki pengaruh yang positif dan resiliensi memiliki pengaruh yang negatif terhadap kecemasan mengerjakan skripsi. Artinya, semakin tinggi tingkat socially prescribed perfectionism, maka semakin tinggi pula kecemasan yang dialami saat mengerjakan skripsi. Sebaliknya, resiliensi yang tinggi akan memprediksi menurunnya kecemasan dalam mengerjakan skripsi. Selanjutnya pada model (3c), interaksi antara socially prescribed perfectionism dengan resiliensi dalam bentuk nilai selisih mutlak dimasukkan sebagai variabel moderator. Hasilnya, diperoleh nilai $p$ lebih besar dari alpha $(p=0,504 ; p>0,1)$ yang berarti resiliensi tidak berperan memoderasi hubungan antara perfeksionisme dengan kecemasan mengerjakan skripsi.

\section{Diskusi}

Penelitian ini dilakukan untuk melihat efek moderasi resiliensi terhadap hubungan antara perfeksionisme dengan kecemasan mengerjakan skripsi, dengan meninjau masing-masing dimensi perfeksionisme, yaitu self-oriented perfectionism, other-oriented perfectionism, dan socially prescribed perfectionism. Hal ini dilakukan karena setiap dimensi perfeksionisme memiliki kontribusi yang berbeda-beda terhadap terjadinya kecemasan.

Hasil penelitian menemukan selforiented perfectionism memiliki pengaruh positif dalam tingkat yang rendah terhadap 
kecemasan mengerjakan skripsi. Selforiented perfectionism termasuk dalam jenis perfeksionisme yang adaptif. Artinya, mahasiswa yang memiliki kecenderungan untuk mencapai standar sempurna untuk dirinya sendiri, khususnya dalam proses pengerjaan skripsi, akan berpotensi mengalami kecemasan dalam tingkat rendah. Kecemasan ini akan mendorong individu mengimbangi dirinya dengan penyelesaian masalah dengan standar tinggi yang dimiliki (Besser et al., 2004; Lessin \& Pardo, 2017). Hasil yang menunjukkan mahasiswa berupaya untuk mengerjakan skripsinya dengan sungguhsungguh, membaca lebih banyak artikel jurnal yang valid, serta melakukan bimbingan dengan dosen pembimbing secara rutin. Hal ini dilakukan agar standar sempurna yang ditetapkannya dapat tercapai. Sejalan dengan penelitian yang menyatakan perfeksionisme yang berorientasi pada diri sendiri akan mendorong mahasiswa dalam penyelesaian masalahnya, yaitu melalui penilaian kembali secara positif mengenai keadaan yang dihadapinya serta merencanakan dengan matang mengenai apa yang akan dilakukannya (Gnilka, Ashby, \& Noble, 2012).

Selanjutnya, hasil yang diperoleh menunjukkan bahwa other-oriented perfectionism tidak memiliki pengaruh terhadap kecemasan mengerjakan skripsi pada mahasiswa. Hal ini dimungkinkan terjadi karena berdasarkan data penunjang yang diperoleh, standar yang dimiliki mahasiswa dalam mengerjakan skripsinya cenderung diperoleh dari adanya tuntutan eksternal. Selain itu, mahasiswa juga tidak terlihat berlebihan dalam menetapkan standar terhadap dirinya dalam mengerjakan skripsi sehingga mereka pun tidak mengarahkan standar sempurnanya kepada orang lain. Hal ini sesuai dengan teori Hewitt \& Flett (1991) bahwa otheroriented perfectionism muncul akibat adanya standar sempurna terhadap diri sendiri yang kemudian ditetapkan kepada orang lain.

Di sisi lain, dimensi socially prescribed perfectionism secara signifikan memengaruhi terjadinya kecemasan dalam mengerjakan skripsi. Sejalan dengan penelitian yang dilakukan sebelumnya bahwa perfeksionisme yang berorientasi sosial ini memiliki kontribusi yang lebih besar dibandingkan dengan tipe perfeksionisme lainnya (Gnilka et al., 2012; Kanten \& Murat, 2015; Lessin \& Pardo, 2017). Socially prescribed perfectionism termasuk ke dalam jenis perfeksionisme yang maladaptif. Ketika mahasiswa mempersepsikan adanya standar yang terlampau tinggi yang ditetapkan oleh orang lain terhadap dirinya, mereka akan cenderung berupaya untuk mencapainya namun didasari oleh perasaan takut akan kegagalan serta selalu merasa tidak cukup atas usaha atau pencapaiannya. Berdasarkan data yang diperoleh, mahasiswa Fakultas Psikologi Unpad angkatan 2016 merasakan adanya harapan dan tuntutan dari lingkungan terhadap dirinya. Misalnya, pihak keluarga dan dosen pembimbing yang memintanya untuk lulus 3,5 tahun, tuntutan untuk melakukan penelitiannya dengan memperhatikan standar dan baku mutu penelitian, serta menguasai dengan baik penelitian yang dilakukannya. Selain itu, mahasiswa juga merasakan adanya standar 
yang tinggi dari dosen pembimbing dalam pengerjaan skripsinya sehingga menyebabkan mereka selalu merasa takut setiap akan melakukan bimbingan. Socially prescribed perfectionism merupakan dorongan perfeksionisme yang bersifat maladaptif sehingga berdampak pada hasil yang negatif, seperti kepuasan hidup yang rendah, burnout, depresi, dan kecemasan (Sheppard \& Hicks, 2017). Sejalan dengan data yang diperoleh bahwa berbagai tuntutan yang dialami selama mengerjakan skripsi membuat sebagian besar mahasiswa mengalami berbagai reaksi negatif, baik secara fisik, seperti sakit kepala, diare, maag, inflamasi pada kulit, hingga tidak lancarnya siklus haid pada mahasiswi, maupun psikis, seperti cemas, gelisah, sedih, murung, tertekan, sering menangis, overthinking, helplessness, denial, flight hingga terjadi prokrastinasi dan tidak termotivasi untuk mengerjakan skripsi.

Kemudian, penelitian ini juga menemukan bahwa secara parsial resiliensi signifikan berpengaruh terhadap kecemasan mengerjakan skripsi. Nilai koefisien yang diperoleh menunjukkan bahwa resiliensi memiliki pengaruh yang negatif terhadap kecemasan mengerjakan skripsi. Artinya, semakin tinggi tingkat resiliensi yang dimiliki dapat menurunkan tingkat kecemasan yang dialami dalam proses mengerjakan skripsi. Sesuai dengan penelitian sebelumnya, bahwa resiliensi yang tinggi berasosiasi positif dengan rendahnya tingkat psychological distress pada mahasiswa (Hjemdal, Friborg, Stiles, Martinussen, \& Rosenvinge, 2006; Stallman, 2011). Meskipun demikian, resiliensi tidak mampu berperan sebagai moderator terhadap hubungan antara perfeksionisme, baik self-oriented maupun socially prescribed perfectionism, dengan kecemasan. Artinya, dalam kasus ini, resiliensi tidak dapat melemahkan hubungan antara keduanya. Hal ini dimungkinkan terjadi karena tidak semua dimensi resiliensi yang diukur dalam penelitian ini dihayati oleh mahasiswa dalam menurunkan kecemasan mengerjakan skripsi akibat adanya tuntutan dan standar dari lingkungannya. Berdasarkan data yang diperoleh, mahasiswa hanya menghayati dukungan sosial yang memiliki pengaruh besar dalam mengatasi kecemasan yang dialaminya dalam mengerjakan skripsi.

Di sisi lain, diperoleh dari pertanyaan terbuka yang diberikan, hasil penelitian menunjukkan hambatanhambatan yang dirasakan mahasiswa dalam mengerjakan skripsinya. Mayoritas mahasiswa merasakan hambatan terbesar dalam pengerjaan skripsinya ialah berkaitan dengan dirinya sendiri, seperti rasa malas, bosan, kurangnya motivasi, capek, bingung harus memulai dari mana, kejenuhan, serta sulitnya memanajemen waktu. Selain itu, mahasiswa juga mengaku bahwa mereka masih mendapatkan tugas lain, baik akademik maupun nonakademik. Hal ini menyebabkan mahasiswa menunda atau prokrastinasi terhadap pengerjaan skripsinya. Resiliensi dibutuhkan individu untuk bangkit kembali dan merespons keadaan yang stresful secara aktif dan positif (Huang \& Lin, 2013) serta membantunya untuk bertahan atas pencapaiannya (Gartland, Bond, Olsson, Buzwell, \& Sawyer, 2011). Sementara, karakteristik mahasiswa dalam penelitian ini cenderung mengalami hambatan untuk meregulasi dirinya dibandingkan dengan 
tekanan yang diterima dalam pengerjaan skripsinya.

\section{Kesimpulan}

Berdasarkan analisis data yang telah dilakukan, dapat disimpulkan bahwa penelitian tidak menemukan efek moderasi resiliensi terhadap hubungan antara perfeksionisme dengan kecemasan mengerjakan skripsi. Di sisi lain, penelitian ini dapat membuktikan bahwa perfeksionisme yang berorientasi pada diri sendiri dan sosial dapat memprediksi terjadinya kecemasan mahasiswa dalam mengerjakan skripsinya. Artinya, semakin tinggi tingkat perfeksionisme akan menghasilkan kecemasan yang tinggi pula. Sebaliknya, meskipun tidak dapat berperan sebagai moderator, resiliensi secara parsial juga memiliki pengaruh, yaitu dapat menurunkan kecemasan mahasiswa dalam proses pengerjaan skripsinya.

Saran

Hasil penelitian yang diperoleh dapat menjadi masukan bagi peneliti selanjutnya untuk mempertimbangkan faktor lain yang dapat berpotensi sebagai moderator terhadap hubungan antara perfeksionisme dan kecemasan mahasiswa dalam mengerjakan skripsi, seperti dukungan sosial, regulasi diri, motivasi diri, dan manajemen waktu. Secara praktis, hasil penelitian ini dapat dimanfaatkan untuk membantu mahasiswa merefleksi diri bahwa adanya tuntutan dan harapan yang mungkin diperoleh dari lingkungan dalam mengerjakan skripsinya sehingga mereka dapat lebih mengantisipasi dampak yang mungkin terjadi. Selain itu, bagi dosen pembimbing mahasiswa skripsi, hasil penelitian ini diharapkan dapat memerhatikan standar-standar yang ditetapkan dengan kemampuan mahasiswanya dalam mengerjakan skripsi. Selain itu, memberikan dukungan sosial dapat membantu mahasiswa dalam menjalani proses pengerjaan skripsi sehingga mengurangi potensi terjadinya kecemasan.

\section{Daftar Pustaka}

Aslinawati, E. N., \& Mintarti, S. U. (2018). Keterlambatan penyelesaian skripsi mahasiswa angkatan 2012 (Studi kasus di Jurusan Ekonomi Pembangunan Fakultas Ekonomi Universitas Negeri Malang). Jurnal Pendidikan Ekonomi, 10(1), 26-37. doi: https://doi.org/10.17977/um014v10i120 $\underline{17 p 026}$

Barseli, M., \& Ifdil, I. (2018). Konsep stres akademik siswa. Jurnal Konseling Dan Pendidikan, 5(3), 143. doi: https://doi.org/10.29210/119800

Besser, A., Flett, G. L., \& Hewitt, P. L. (2004). Perfectionism, cognition, and affect in response to performance failure vs . success. Journal of RationalEmotive and Cognitive-Behavior Therapy, 22, 297-324. doi: https://doi.org/10.1023/B:JORE.0000047 313.35872.5c

Dancey, C. P. \& Reidy, J. (2007). Statistics without maths for psychology. London: Pearson Education.

Eddington, K. M. (2014). Perfectionism, goal adjustment, and self-regulation: A short-term follow-up study of distress 
and coping. Self and Identity, 13(2), 197213. doi: https://doi.org/10.1080/15298868.2013.7 $\underline{81740}$

Etikan, I., Musa, S. A., \& Alkassim, R. S. (2016). Comparison of convenience sampling and purposive sampling. American Journal of Theoretical and Applied Statistics, 5(1), 1-4. doi: https://doi.org/10.11648/j.ajtas.2016050 $\underline{1.11}$

Flett, G. L., Hewitt, P. L., Blankstein, K. R., \& O'Brien, S. (1991). Perfectionism and learned resourcefulness in depression and self-esteem. Personality and Individual Differences, 12(1), 61-68. doi: https://doi.org/10.1016/01918869(91)90132-U

Gartland, D., Bond, L., Olsson, C. A., Buzwell, S., \& Sawyer, S. M. (2011). Development of a multi-dimensional measure of resilience in adolescents: The Adolescent Resilience Questionnaire. BMC Medical Research Methodology, 11(1), $134 . \quad$ doi: https://doi.org/10.1186/1471-2288-11$\underline{134}$

Gnilka, P. B., Ashby, J. S., \& Noble, C. M. (2012). Multidimensional perfectionism and anxiety: Differences among individuals with perfectionism and tests of a coping-mediation model. Journal of Counseling \& Development, 90(4), 427-436. doi: https://doi.org/10.1002/j.15566676.2012.00054.x

Gunawati, R., Hartati, S., \& Listiara, A. (2006). Hubungan antara efektivitas komunikasi mahasiswa dan dosen pembimbing utama skripsi dengan stres dalam menyusun skripsi pada mahasiswa Program Studi Psikologi Fakultas Kedokteran Universitas Diponegoro. Jurnal Psikologi, 3(2), 93115.

Hayes, A. F. (2018). Introduction to mediation, moderation, and conditional process analysis. (Edisi kedua). New York: The Guilford Press.

Hewitt, P. L., \& Flett, G. L. (1991). Perfectionism in the self and social contexts: Conceptualization, assessment, and association with psychopathology. Journal of Personality and Social Psychology, 60(3), 456-470. doi: $\quad$ https://doi.org/10.1037/0022$\underline{3514.60 .3 .456}$

Hewitt, P. L., \& Flett, G. L. (2002). Perfectionism and stress processes in psychopathology. In G. L. Flett \& P. L. Hewitt (Eds.), Perfectionism: Theory, research, and treatment (p. 255-284). American Psychological Association.

Hjemdal, O., Friborg, O., Stiles, T. C., Martinussen, M., \& Rosenvinge, J. H. (2006). A new scale for adolescent resilience: Grasping the central protective resources behind healthy development. Measurement and Evaluation in Counseling and Development, 39(2), 84-96. doi: https://doi.org/10.1080/07481756.2006.1 1909791

Hong, Y.-y., Chiu, C.-y., Dweck, C. S., Lin, D. M.-S., \& Wan, W. (1999). Implicit theories, attributions, and coping: A meaning system approach. Journal of Personality and Social Psychology, 77(3), 588-599.

doi:

\section{https://doi.org/10.1037/0022-}

$\underline{3514.77 .3 .588}$

Huang, Y. C., \& Lin, S. H. (2013). 
Development of the Inventory of College Students' Resilience and evaluating the measurement invariance. British Journal of Guidance $\mathcal{E}$ Counselling, 41(5), 471-486. doi: https://doi.org/10.1080/03069885.2012.7 $\underline{49973}$

Kanten, P., \& Murat, Y. (2015). The effects of positive and negative perfectionism on work engagement, psychological well-being and emotional exhaustion. Procedia Economics and Finance, 23, 1367-1375. doi:

https://doi.org/10.1016/S2212-

5671(15)00522-5

Lessin, D. S., \& Pardo, N. T. (2017). The impact of perfectionism on anxiety and depression. Journal of Psychology and Cognition, 2(1), 78-82. doi: https://doi.org/10.35841/psychologycognition.2.1.78-82

Masten, A. S. (2001). Ordinary magic: Resilience processes in development. American Psychologist, 56(3), 227-238. doi: $\quad$ https://doi.org/10.1037/0003066X.56.3.227

Rachmawati, D. I., Yuniarti, D., \& Nohe, D. A. (2015). Model regresi variabel dengan metode selisih mutlak. Jurnal Eksponensial, 6(2), 187-192.

Sari, J., \& Suhariadi, F. (2019). Kontrak psikologis terhadap commitment to change: Resiliensi akademik sebagai variabel mediasi. Persona: Jurnal Psikologi Indonesia, 8(2), 178-192. doi: https://doi.org/10.30996/persona.v8i2.2 $\underline{535}$

Sheppard, L., \& Hicks, R. (2017). Maladaptive perfectionism and psychological distress: The mediating role of resilience and trait emotional intelligence. International Journal of Psychological Studies, 9(4), 65-75. doi: https://doi.org/10.5539/ijps.v9n4p65

Siswanto, I., \& Sampurno, Y. G. (2013). Faktor-faktor penghambat dalam pengerjaan tugas akhir skripsi mahasiswa FT UNY.Jurnal Taman Vokasi, 3(1), 629-642.

Spielberger, C. D. (1966). Theory and research on anxiety. In C. D. Spielberger, Anxiety and behavior. New York: Academic Press.

Stallman, H. M. (2011). Psychological distress in university students: A comparison with general population data. Australian Psychologist, 45(4), 249257.

doi:

https://doi.org/10.1080/00050067.2010.4 $\underline{82109}$

Wiyatmo, Y., Mundilarto, Suharyanto, \& Widodo, E. (2010). Efektivitas bimbingan tugas akhir skripsi (TAS) Mahasiswa Jurusan Pendidikan Fisika FMIPA UNY. Dalam Prosiding Seminar Nasional Penelitian, Pendidikan dan Penerapan MIPA, hal. 405-414. Fakultas MIPA, Universitas Negeri Yogyakarta, Yogyakarta. 